\title{
Ni rojos ni ateos: las difíciles relaciones editoriales entre la España franquista y el exilio argentino ${ }^{1}$
}

Neither Red nor Atheist: the uneasy publishing relationships between Francoist Spain and the Argentinian Exile

\section{ANA MARTÍNEZ RuS \\ UNIVERSIDAD COMPLUTENSE DE MADRID(ESPAÑA) · amartine@ucm.es}

Ha centrado su investigación en la historia sociocultural, especializándose en la historia de la edición y de la lectura en España en el siglo XX, con especial atención a los años treinta y a la represión cultural de la dictadura en el mundo del libro y de la edición.

Ha publicado diversos trabajos, entre ellos, destaca La política del libro durante la Segunda República: socialización de la lectura (Gijón, Trea, 2003) o La lectura en la época contemporánea junto a Raquel Sánchez( Arco/Libros, 2010). Recientemente ha publicado La persecución del libro: hogueras, infiernos y buenas lecturas (1936-1951) (Gijón, Trea, 2014).

RESUMEN: En este artículo se abordan las difíciles relaciones editoriales entre la España de Franco y el exilio argentino debido a la censura. La industria editorial argentina se desarrolló publicando los originales y traducciones prohibidas en la Península y con la colaboración de profesionales del libro y autores exiliados. Estas obras llegaban con notables obstáculos en pequeñas cantidades y para un público muy reducido.

PALABRAS ClaVE: Losada, literatura argentina, Guillermo de Torre.
ABSTRACT: This study approaches the difficult editorial relationships between Franco's Spain and the Argentine exile because of censorship. Argentina's publishing industry developed the originals and translations prohibited in Spain and in collaboration with book professionals and exiled authors. These books came with significant obstacles in small quantities and for a very small audience.

KEY WORDS: Publishing, Francoist Spain, Argentina, Losada.

\footnotetext{
${ }^{1}$ Este trabajo se inserta en el Proyecto de Investigación del Ministerio de Economía y Competitividad, HAR 2014-51883-P:

“Scripta in itinere'. Discursos, formas y apropiaciones de la cultura escrita en espacios públicos desde la Primera Edad Moderna a nuestros días", dirigido por Antonio Castillo Gómez.
}

Martínez Rus, Ana. "Ni rojos ni ateos: las difíciles relaciones editoriales entre la España franquista y el exilio argentino". Kamchatka. Revista de análisis cultural 7 (Junio 2016): 11-33

DOI: 10.7203/KAM.7.7683 ISSN: 2340-1869 
La victoria franquista tuvo consecuencias fatales para la industria editorial y el comercio de librería. Todas las actividades industriales y negocios se vieron afectados por la dura posguerra y la política autárquica. Pero sin duda el mundo del libro fue el sector más perjudicado ya que, aparte de soportar la falta de suministros, los cortes de electricidad o la escasez de divisas, tuvo que hacer frente al sistema censor. La censura condicionó toda la producción editorial española durante la dictadura (Larraz, 2014). Así, el régimen obligó a todas las firmas que reanudaron su actividad después de la guerra a rehacer sus catálogos por completo. De hecho desaparecieron colecciones enteras dedicadas a temas políticos o sociales para dejar paso a series de santos o de héroes de la Cruzada. Por ejemplo, Biblioteca Nueva tuvo que suprimir su colección "Las nuevas doctrinas sociales", que recogía títulos de Lenin, Kautsky y Kerenski. La Editorial Aguilar también eliminó de su fondo la "Biblioteca de ideas y estudios contemporáneos", donde había publicado textos de Plejánov y Proudhon o El capital de Marx. A cambio, Biblioteca Nueva sacó una serie "Vida de santos españoles" con títulos como San Juan de Dios de Mariano Tomás, Santo Toribio, obispo de Astorga (un momento de la formación de España) de Luis Alonso Luengo o Santo Domingo de Guzmán de Luis Alonso Getino, todos en 1939. La casa Aguilar también publicó una colección religiosa "Razonemos nuestra fe", donde aparecieron títulos como Cristo Rey o Jesucristo y nuestro siglo de Tihamer Tóth o Jesucristo de Vicente de Pereda en 1939, y Meditaciones del Doctor de la Iglesia San Agustín en 1940. Asimismo sacó títulos como Asalto a la Cárcel Modelo (22 de agosto de 1936) de Francisco Pino, Lira de flechas: versos de la Quinta Columna de Enrique Castaño Gallesta en 1939, y El comunismo en España: treinta y dos meses de barbarie en la zona roja de Carolina Peralta en 1940.

El panorama literario al final de la guerra era, al decir de José-Carlos Mainer, desolador, ya que "el manjar más prodigado" fueron los libros que recogieron "el anecdotario sangriento de la vida en la España republicana. La burguesía atemorizada -explica Mainer- venga de esa manera los agravios inferidos por la "horda" en los años frentepopulistas" (Mainer, 1971: 46). En esta línea otros sellos publicaron títulos como Preventorio D: ocho meses en el SIM de Félix Ros en la editorial Yunque en 1939, Checas de Madrid de Tomás Borrás del mismo año en Ediciones Españolas, Una isla en el mar Rojo de Wenceslao Fernández Flórez en el mismo sello en 1940, o Cristo en los infiernos de Ricardo León en la Librería Victoriano Suárez en 1941. Asimismo proliferaron los títulos de carácter religioso, sin olvidar los relacionados con la versión oficial de la guerra civil. En la casa Sopena publicaron España vence a la Internacional comunista de José Ramblas en 1939, y Episodios de la Historia Sagrada: Antiguo Testamento en 1940. En Espasa-Calpe salió Calvo Sotelo: una vida fecunda, un ideario político, una doctrina económica de Aureli Joaniquet y El cristianismo como doctrina y como vida de Juan 
Zaragüeta, ambos de 1939. También tuvieron mucho éxito los libros que recogían acontecimientos y operaciones bélicas de la segunda guerra mundial (Mainer, 1989: 245-268).

La proliferación de este tipo de obras y la reconversión de los fondos editoriales respondían a la necesidad de sustituir todo el patrimonio bibliográfico destruido y depurado durante la guerra y la posguerra por buenas lecturas acordes con los principios del nacionalcatolicismo. No podemos olvidar que en la España de Franco se quemaron millones de publicaciones en hogueras purificadoras. En cada plaza de los pueblos que se iban ocupando militarmente se organizaron quemas públicas del veneno escrito como acto fundacional del nuevo Estado. Asimismo se trituraron otros tantos kilos de libros con guillotinas con el fin de convertirlos en pasta de papel para los nuevos títulos imperiales y de mártires que se editaron. El fuego resultó más simbólico y efectivo en la eliminación de las ideas del enemigo que la afilada hoja de metal en la aniquilación de páginas. Con las teas incandescentes toneladas de volúmenes fueron reducidos a cenizas, quedando solo el olor a papel y cartón quemado y el polvo de tanta infamia. Aunque menos poética, la guillotina permitía reaprovechar las virutas de papel en pasta para nuevos ejemplares. La causa para esta pena tan severa se debía a que esas páginas eran las responsables de la guerra civil, según las autoridades militares, eclesiásticas y civiles que se sublevaron el 18 de julio de 1936. Los textos y las ideologías de esos libros eran culpables. El “alzamiento" que había salvado España del comunismo, el ateísmo y la masonería también había librado a los españoles de esos contenidos ponzoñosos. De este modo se atajó la infección que se había extendido por todo el país: extirpando los malos libros y sus ideas nocivas para proteger así las mentes y las almas de los buenos patriotas. El franquismo fue un régimen represivo de exclusión ideológica y social (Aróstegui Sánchez, 1996: 31-46; y 2012: 423-456.). La represión fue sistémica porque afectó a todos los aspectos de la sociedad española durante casi cuarenta años. La represión cultural, basada en la quema de publicaciones, la censura y en el control de la información, formó parte de la represión generalizada de los militares sublevados y fue un capítulo más de la violencia ejercida por el régimen franquista. La dictadura militar persiguió todo aquello que representaba la Anti-España: eliminó y encarceló personas, ilegalizó partidos y sindicatos, destruyó publicaciones, depuró bibliotecas, y prohibió obras en un intento de borrar las ideas de los enemigos de la sociedad española. El objetivo era limpiar y purificar el país de las ideas subversivas que habían adulterado las esencias españolas. Se trataba de suprimir el pensamiento de los vencidos e imponer el de los vencedores.

La censura formaba parte del ciclo represivo contra el libro, era un eslabón más, pero no el único ni el más grave, aunque tuvo más largo recorrido. Primero se destruyeron los fondos editoriales y bibliotecarios del país, quemando y guillotinando todo tipo de publicaciones, luego se expurgaron y depuraron las colecciones bibliográficas de los anaqueles de las bibliotecas, de los almacenes de las editoriales y de los escaparates de las librerías. A continuación se estableció la censura previa para 
controlar la oferta nacional e internacional e impedir que salieran al mercado títulos prohibidos y perjudiciales, y por último se publicaron textos sanos de acuerdo con el nuevo decálogo franquista, en muchos casos con fines propagandísticos. La censura por sí sola no tenía sentido, o al menos resultaba insuficiente sin los otros elementos del protocolo punitivo. La legislación y las acciones de los militares rebeldes fueron muy explícitas y expeditivas al respecto desde el comienzo de la contienda. No bastaba solo con destruir los títulos presentes, ni siquiera con purgar los catálogos de las editoriales y los fondos de las bibliotecas, y tampoco era suficiente con recluir obras en salas especiales para la consulta restringida tan solo a especialistas, ni con prevenir la oferta científica y literaria con la censura, ni con sustituir toda esa producción bibliográfica malévola por otra complaciente con el régimen y la Iglesia. $\mathrm{Si}$ solo se atendía al patrimonio bibliográfico existente podrían aparecer nuevas obras perniciosas, y si sólo se prohibían los nuevos títulos podrían circular todas las obras publicadas desde los inicios del liberalismo. Así que era tan necesario ocuparse de las estanterías de las bibliotecas públicas y privadas, y de los fondos editoriales, de librerías y de quioscos, como controlar los catálogos y novedades editoriales de sellos nacionales y extranjeros. Llamas y cuchillas acabaron con toneladas de obras, pero posteriormente y a la vez se fiscalizaron fondos para apartar muchos títulos al gran público, reservándolos sólo a usuarios autorizados y cualificados. Una vez limpia la patria de esa podredumbre intelectual, se establecieron los filtros necesarios para impedir la aparición de esos libros o de otros similares e igualmente peligrosos. De este modo se procuró no dejar resquicio para que se colaran las ideas de la anti-España. Los libros y las ideologías subversivas habían encolerizado a millones de personas, provocando la muerte, el asesinato, la destrucción, el saqueo... En definitiva eran los primeros y directos culpables de la gran hecatombe que vivió el país. Por todo ese mal causado, el castigo debía ser ejemplar y contundente para esos libros criminales y delincuentes. Su aniquilación formó parte del mismo sistema represivo que eliminó personas y privó de libertad a otras muchas. ${ }^{2}$

La censura, en su versión más dura, recogida en la eufemística ley de Prensa de 23 abril de 1938 (fecha de la Fiesta del Libro), impidió que se atacara al régimen y a la Iglesia, que acabó imponiendo su moral pacata y restrictiva ya que en muchos casos se siguieron las indicaciones del Índice Romano. Tampoco se permitían los títulos subversivos, disolventes, o pornográficos. Además ese mismo mes se aprobó otra orden para aplicar el contenido del decreto de diciembre de 1936 sobre la declaración de ilicitud de la producción, comercio y circulación de material impreso pornográfico y disolvente a las obras procedentes del extranjero. Se estrechaba el círculo, el libro era siempre sospechoso y la mayoría de las veces culpable. Atendiendo a los criterios de censura establecidos resultó difícil que la producción literaria de los vencidos pudiera llegar a la Península, y más todavía que fuera publicada por editoriales españolas. Además no podemos olvidar que toda la labor cultural del exilio se orientó a luchar contra el

2 Vid. Ana Martínez Rus, 2012: 365-415; 2013; 2014; y Ana Martínez Rus y Verónica Sierra Blas, 2012: 143-157. 
olvido y la manipulación del pasado reciente en la historia de España, recuperando la memoria y reivindicando la democracia republicana. Las distintas actividades de los emigrados políticos trataron de continuar con la experiencia educativa y cultural de la Segunda República. La letra impresa se convirtió en arma política contra la dictadura militar salida de la guerra civil, que había obligado a miles de españoles a abandonar país. Por tanto no estaba permitida la entrada legal de libros considerados rojos y ateos en la España de Franco.

Asimismo la producción y el comercio del libro durante el franquismo se vio condicionado por la constitución del Instituto Nacional del Libro Español (INLE) el 19 de abril de 1941, aunque con anterioridad, el 23 de mayo de 1939, ya había sido creado el Instituto Nacional del Libro por la Subsecretaría de Prensa y Propaganda, dependiente del Ministerio de la Gobernación, como "único organismo central de consulta y dirección de todos los problemas relativos a la producción y difusión del libro español” encargado de la política del libro. El decreto de creación fue redactado en Burgos por Joaquín Calvo Sotelo, exsecretario de la Cámara del Libro de Madrid, Alfonso Matons, exsecretario de la Cámara de Barcelona, y Pedro Laín Entralgo, jefe de la Sección de Ediciones. ${ }^{3}$ Sin embargo, el reglamento del Instituto no se aprobó hasta dos años después, en abril de de 1941 y por decreto en 1943. ${ }^{4} \mathrm{Al}$ INLE se le encomendó la dirección de la política oficial del libro español, la ordenación sistematizada a través de publicaciones bibliográficas y la protección comercial. Además, su constitución conllevó la desaparición de las Cámaras Oficiales del Libro de Barcelona y de Madrid, creadas respectivamente en 1918 y 1922 y cuyos bienes pasaron a formar parte del patrimonio del INLE, ya que el Instituto asumía todas las funciones de las Cámaras, según el artículo 58 de su reglamento. El primer director del Instituto fue el falangista Julián Pemartín aunque inicialmente este cargo se adjudicó a Pedro Laín Entralgo por el entonces delegado nacional de Propaganda, Manuel Torres López. La intervención estatal llegó a obligar, por orden de marzo de 1941, a los editores a presentar los planes de trabajo semestrales a la Dirección General de Propaganda para buscar su aprobación porque era "misión del Estado vigilar escrupulosamente la producción del libro en todos sus aspectos”. No solo se ocupaba de "la censura literaria en cuanto a la limpieza moral y a la exactitud política" sino también de regular el mercado debido a la escasez de papel. Se perseguía evitar que obras interesantes y útiles no pudieran ser editadas por las carencias de la materia prima básica mientras obras innecesarias o secundarias llegaban a

3 Destaca el informe que la Cámara Oficial del Libro de Barcelona envió con fecha de 11 de febrero de 1939 al Jefe del Servicio Nacional de Archivos y Bibliotecas, Javier Lasso de la Vega, sobre la situación de la industria editorial y librera del país, en Biblioteca Bergnes de las Casas (BBC), Biblioteca Nacional de Cayalunya (BNC), caja núm. 146. En esta memoria se señala la necesidad de crear un organismo ordenador de la política del libro ya sea un Instituto del Libro o bien las Cámaras del Libro, pero no se concibe la convivencia de ambas entidades, aunque lógicamente reconoce la actividad desarrollada hasta entonces por las corporaciones del libro.

4 Vid. Reglamento del Instituto Nacional del Libro Español, Madrid, 1941 y Manfredi, 1963. 
ver la luz. El objetivo era evidente: controlar la producción bibliográfica del país, aparte de la censura previa. En esta misma línea, otro decreto de septiembre de 1941 hacía necesario un visado previo del Ministerio del Ejército para publicar obras referentes a la "guerra de liberación", aparte de la consabida autorización sobre censura. Asimismo otra orden de 25 de noviembre ampliaba la de marzo sobre la obligación de presentar los planes editoriales. Como la Subsecretaría de Prensa y Propaganda pasó a depender de la Vicesecretaría de Educación Popular de FET y de las JONS por ley del 20 de mayo de 1941, cada casa debía, al lanzar una obra al mercado, enviar a la Secretaría de Ediciones de la Delegación Nacional de Propaganda de la Vicesecretaría de Educación Popular un ejemplar de la misma, acompañado de una declaración jurada en la que debía consignarse el día de aparición de dicha obra en las librerías. Se ampliaban las trabas y trámites burocráticos para estrechar la vigilancia sobre el mercado del libro y la oferta bibliográfica. En el segundo artículo se establecían sanciones de entre 500 y 5000 pesetas a aquellas firmas que no presentaran los planes editoriales, y en casos de reincidencia se contemplaba la suspensión temporal de las actividades editoriales. ${ }^{5}$ En julio de 1944 una orden firmada por el secretario general del Movimiento y ministro José Luis Arrese suprimía la presentación obligatoria al Instituto del Libro de los planes semestrales de edición debido a que se había declarado la venta libre del papel de edición.

El comercio de librería extranjera se vio muy perjudicado debido a las restricciones impuestas por la censura, aparte de las trabas burocráticas para conseguir las licencias de importación y las dificultades para obtener divisas, sobre todo durante el período de la autarquía económica. Los trámites resultaban prolijos y lentos. En primer lugar era imprescindible la concesión de las licencias de importación por el Instituto Nacional del Libro Español. Después, atendiendo a las divisas adjudicadas por el Instituto de Moneda Española, debía abonar el pago y una vez llegados los libros a la aduana o estafeta de Correos para recogerlos necesitaba la autorización de entrada y circulación de libros aprobada por la Dirección General de Propaganda. De hecho los profesionales se quejaban amargamente de que todos sus clientes estaban interesados en la compra de libros extranjeros y de que no podían reanudar la importación de publicaciones al ritmo y manera anterior a la guerra sino con arreglo a los cupos de divisas del INLE. Como las cantidades concedidas eran muy escasas no se podían satisfacer las necesidades de todos los compradores. En concreto, León Sánchez Cuesta reclamaba al propio Instituto en diciembre de 1949 la adjudicación de más divisas para el normal funcionamiento de su negocio atendiendo a la rápida inversión que hacía de las cantidades asignadas. Tan solo había conseguido algunas cantidades de libras, francos, liras e incluso florines, pero nunca había recibido dólares. Además justificaba la continua necesidad de moneda extranjera por las características de su clientela, principalmente bibliotecas universitarias, profesores, centros de investigación y de estudio. Dado que reunía los criterios

5 En BOE, 30 de noviembre de 1941. 
preferentes establecidos para la asignación, solicitaba la entrega de nuevas divisas en caso de rectificaciones futuras de los cupos, o en el de reparto de cantidades no utilizadas por sus colegas, o bien las sobrantes de cantidades no distribuidas (Martínez Rus, 2007: 131-145).

La censura, además, perjudicó la proyección exterior de la industria del libro española contribuyendo al desarrollo de los sellos americanos. Estas empresas se ocuparon de publicar todos los textos en español, traducciones y originales prohibidos en la España de Franco. Además estas casas contaron con la colaboración de numerosos profesionales e intelectuales exiliados. Fue el caso de profesionales consagrados como Rafael Giménez Siles, José Venegas o Antonio López Llausás, o bien de nuevos editores y libreros como Juan Grijalbo o Benito Milla. ${ }^{6}$ Además, otros muchos participaron activamente en el mundo del libro como directores de colecciones, autores, traductores o críticos, o bien como ilustradores, correctores, impresores, distribuidores y libreros. Sólo en México surgieron más de treinta editoriales impulsadas por españoles, entre las que destacan Editorial B. Costa-Amic, Proa, Leyenda, Séneca, Ediapsa, Grijalbo, UTEHA, Porto, Joaquín Mortiz, Era, Ediciones Rex, Atlántida, Ediciones España, Minerva, Jurídicas Hispanoamericanas, Lex, Magister, Cima, Lemuria, Moderna, Norte, Continental, Orión, Quetzal, Nueva España, Biblioteca Catalana, Xótchitl, Alejandro Finisterre o Esfinge. Asimismo colaboraron con el Fondo de Cultura Económica desterrados como Manuel Andújar, Enrique y Joaquín Díez-Canedo, Bernardo Giner de los Ríos, Agustín Millares Carlo, José Gaos, León Felipe, Eduardo Nicol o Wenceslao Roces (Díaz Arciniega, 1996). Otras tantas librerías fueron fundadas por exiliados: la Librería Juárez, la Cide, la Librería de Santiago Ballescá, El Gusano de Luz, Librería Técnica, Góngora, Ideea, Quetzal, Madero, Librería General, Librerías Cristal, UDE o México Lee (Santonja, 1997 y 2003; Suárez, 1982: 601-621; y Férriz Roure, 1980). En Argentina también fue intensa la labor de editoriales creadas por españoles como Losada, Sudamericana, Emecé, Nova, Botella al Mar, Pleamar, Nuevo Romance, Poseidón, Vasca Ekin, Ediciones Jurídicas Europa-Américo, Oberón, Periplo y Bajel, sin contar la intervención en casas ya establecidas como Americalee, Atlántida, Aniceto López, Omeba, Schipire, El Ateneo o Antonio Zamora, donde trabajaron y publicaron españoles expatriados (Pochat, 199: 163-176; y Sagastizábal, 1991: 259-272). Por último conviene señalar la labor de estas editoriales en la publicación de autores del interior que no podían sacar sus obras por problemas con la censura. Este fue el caso de La colmena de Camilo José Cela, que apareció en Argentina en Emecé en 1951, o de Señas de identidad de Juan Goytisolo, que salió en México en Joaquín Mortiz en 1967.

Las editoriales americanas, especialmente las mexicanas y argentinas, eran mejores que las españolas en calidad tipográfica y contenidos porque recogían la producción de los intelectuales

\footnotetext{
6 Julián Amo y Charmion Shelby, 1950 y Fernando Piedrafita Salgado, 2003, recogen buena parte de la producción exiliada.
} 
desterrados y de todas las obras prohibidas en la península. Estas casas despegaron después de la guerra civil con la participación de muchos profesionales del libro exiliados y continuaron siendo superiores a las españolas hasta los años sesenta. Por otra parte, la producción española de posguerra, con un nivel científico e intelectual bajo, controlada por la dictadura y con impresiones y papeles deficientes, no resultaba, lógicamente, atractiva para el público americano. Sobre este particular destaca un artículo traducido del periodista y escritor Herbert Rutledge Southworth (aunque aparece como Souphworth), que recogió la Cámara del Libro de Barcelona, titulado "Editores españoles en el destierro" y fechado en junio de 1940. Southworth supo describir, con gran clarividencia y rapidez, el nuevo panorama editorial en América Latina, así como los cambios operados tras las condiciones de producción, edición y venta de libros impuestas en la España por la dictadura de Franco. A los profesionales catalanes, tradicionalmente más volcados hacia el mercado americano, les interesaba notablemente conocer la edición y el comercio de libros en aquellas plazas. De ahí que se hicieran rápidamente con este artículo que proporcionaba tantos datos interesantes sobre el mundo del libro en América y en el interior de la península. En relación con las expectativas de negocio, era imprescindible para las casas catalanas conocer de primera mano las consecuencias del exilio español y de la censura franquista en la edición y difusión del libro en castellano, sobre todo la actividad de los republicanos desterrados en México y en otros países del hemisferio austral. Este amplio artículo repasaba igualmente la industria editorial durante la guerra civil, y subrayaba el importante desarrollo alcanzado por los sellos americanos debido al impulso de los profesionales españoles exiliados.

La victoria del general Franco y sus aliados nazi-fascistas ha determinado significativos cambios en el mundo de la producción y edición españolas, no sólo en España sino también en América española. Actualmente el Nuevo Mundo puede vanagloriarse de poseer el sector más importante de la industria editorial española, así como la hegemonía en las actividades intelectuales españolas.

Antes de la guerra las principales editoriales españolas radicaron en Madrid y Barcelona; con sucursales en la América del Sud [sic] y en México, dominaban los mercados de toda la América latina. Los escritores hispano americanos buscaban ansiosamente la distinción de ver publicados sus libros en España para exportarlos después a sus países nativos. La guerra ha provocado cambios radicales en la situación aludida. Actualmente, la elite de escritores españoles -los que han sobrevivido a la guerra- se halla en el destierro y sus obras están prohibidas tanto por lo que respecta a la edición como a la circulación, en la España fascista de Franco. ${ }^{7}$

\footnotetext{
7 Herbert Rutledge Southworth, "Editores españoles en el destierro", artículo traducido de Publishers Weekly, del 8 de junio de 1940, p. 1. Esta revista estadounidense especializada fue fundada en 1872 para editores, libreros, bibliotecarios y agentes literarios. Recogido por la Cámara Oficial del Libro de Barcelona, en Biblioteca Nacional de Catalunya, Sala Bergnes de las Casas, caja 146.
} 
Este historiador estadounidense recogía las actividades de los nuevos sellos fundados por exiliados españoles, principalmente en México. Con gran conocimiento del mundo editorial y de su evolución durante la guerra civil, aparte de una clara simpatía hacia la República española, daba cuenta de los profesionales e intelectuales que estaban detrás de cada aventura editorial, así como de los colaboradores y directores de las colecciones y detallaba muchos de los títulos publicados. Cabe destacar que este hispanista publicó en 1963 en la mítica editorial antifranquista de París Ruedo Ibérico El mito de la cruzada de Franco, obra que cuestionaba la historia oficial del régimen. Por este motivo el Ministerio de Información y Turismo, encargado de la censura y con Manuel Fraga Iribarne al frente, creó el Gabinete de Estudios sobre Historia, Sección de Estudios sobre la Guerra de España bajo la dirección del historiador gubernamental Ricardo de la Cierva, con el objetivo de establecer un servicio de contrainformación que detuviese la nueva perspectiva de la historia sobre la contienda española.

Ante las constantes quejas de editoriales sobre la gravedad del problema de la exportación de libros y la imposibilidad de culminar la conquista del mercado sudamericano por falta de producción española, se llevaron a cabo distintas iniciativas para paliar esta situación. Además constaba que las editoriales americanas habían pasado en poco tiempo de 46 a 162. Por ello desde Burgos, en 1937, el jefe del Departamento de Ediciones, Pedro Laín, trató de buscar una rápida resolución a la crisis del papel y propuso el restablecimiento de las primas a la exportación, así como la publicación en España de obras originales de los mejores autores americanos. Y por último, en relación con el tema de la censura, la cuestión más espinosa y más perjudicial para la proyección americana de la industria editorial, planteó la posibilidad de establecer un sistema de censura para los libros destinados al exterior distinto del que se existía para los vendidos en el interior "sin mengua desde luego de los principios básicos políticos, religiosos y morales de nuestro Estado". ${ }^{8}$ Sin embargo, esta propuesta no salió adelante y el Estado franquista hizo muy poco por fomentar la exportación del libro español en América Latina hasta el final del régimen, en pleno desarrollismo y en relación a los cambios generales en política económica tras el Plan Nacional de Estabilización, incluida la fallida ley de Protección del Libro de 1946, más allá de las exenciones de impuestos y las subvenciones al papel que buscaban abaratar el precio final del libro en los mercados exteriores. ${ }^{9}$ En este sentido debido a la "pesada carga de la censura" (Delibes y Vergés, 2002 : 45) y a la prolija burocracia del Instituto del Libro Español, el régimen entorpeció al sector, a pesar del discurso oficial y de la inversión destinada en organismos oficiales y en propaganda para contrarrestar la actividad de los exiliados (Delgado Gómez-Escalonilla, 1992). La situación fue dramática para las antiguas editoriales, ya que después de sobrevivir a los daños y pérdidas de la guerra tuvieron que

8 En AGA, Sección de Educación, caja núm. 1374.

9 Vid. María Fernández Moya, 2008: 97-110; 2009a: 65-77; 2009b: 23-49; 2011: 205-237; y 2015: 575-595. Cfr. Larraz, 2010: 150-156. 
adaptarse a unas circunstancias económicas muy difíciles y rehacer su fondo ante la imposibilidad de reeditar muchos títulos de las colecciones por causa de la censura, aunque hubieran tenido gran aceptación de público y buen nivel de ventas. En algunos casos estos títulos eran clásicos de los sellos, sus mayores éxitos, y llegaron así a desaparecer series completas. De hecho, los editores se quejaban de que las ventas habían bajado un $60 \%$ en torno a 1949 , diez años después de finalizar la contienda. En 1944, el editor catalán Gustavo Gili ya se quejaba, en su obra Bosquejo de una política del libro, del excesivo precio del libro español como consecuencia del encarecimiento de las materias primas, y en especial del papel. El libro corriente de literatura que en 1936 se vendía a 5 pesetas, nueve años después costaba entre 18 y 20 pesetas. Y la novela popular de quiosco cuyo precio oscilaba entre 60 y 90 céntimos entonces costaba entre 3 y 5 pesetas (Gili, 1944: 62-72). Además, en las décadas de los cuarenta y los cincuenta la actividad editorial sufrió un importante descenso por las limitaciones de papel y las restricciones de energía eléctrica que paralizaron la actividad de los talleres. El control político sobre los suministros de papel fue la clave del negocio editorial y constituyó otra forma más, muy eficaz, de censura.

En definitiva la guerra y su desenlace supusieron una cesura en la edición nacional y en las relaciones editoriales e intelectuales con el continente americano. Se interrumpieron los intercambios comerciales, perjudicando notablemente los intereses de las casas españolas, en beneficio de las firmas americanas, que además se aprovecharon de los escritores y profesionales del libro exiliados así como de la censura impuesta en España. Recordemos que a lo largo del primer tercio del siglo XX los editores españoles habían abordado intensamente las plazas americanas, que desde el siglo pasado recibían publicaciones en castellano editadas en Francia, Alemania o Estados Unidos. La industria editorial era necesariamente exportadora debido a las limitaciones del mercado nacional y a las enormes posibilidades de una veintena de países de habla hispana. Asimismo este fenómeno de expansión estaba relacionado con el proceso de modernización industrial y comercial provocado por los avances técnicos, la aparición del editor como profesión autónoma diferenciada del comercio de librería, y la formación de sociedades anónimas. Las casas editoriales, situadas principalmente en Madrid y Barcelona, aumentaron la producción bibliográfica, transformaron la industria librera española, y se encargaron de la exportación a Hispanoamérica (Martínez Rus, 2000: 31-53; 2001: 269-305; 2002: 1021-1058; 2003: 291-366; 2008: 183-204; y 2011: 81-100). Fruto de estos avances surgieron proyectos como el Consorcio Nacional Exportador del Libro en 1929 en Barcelona y el Sindicato Exportador del Libro Español en 1930 en Madrid y, en 1935 la instalación de depósitos de libros en las capitales europeas por el Instituto del Libro Español. Asimismo destacó la exitosa instalación en Buenos Aires del Depósito General de Representación de las editoriales Salvat, Gustavo Gili y Sopena, en 1935 bajo la dirección de Joaquín de Oteyza, como representante exclusivo. Se colocaron doscientos cincuenta mil kilos de libros por un valor 
de 1.300.000 pesetas. Este experimentado viajante de libros por América como representante de Sopena desde 1926 pretendía consolidar estas editoriales catalanas abasteciendo el mercado rápida y racionalmente, sin necesidad de largas esperas. De esta manera con una llamada de teléfono los libreros argentinos podían disponer en pocas horas de los títulos de estas importantes editoriales catalanas (Mangada y Pol, 1996: 117-124).

Los problemas con la edición americana surgieron desde el golpe de Estado de julio del 36. Así en el periódico falangista publicado en Pamplona jArriba España! y dirigido por el religioso Fermín Yzurdiaga, que acabó siendo Jefe Nacional de Prensa y Propaganda, en un artículo con motivo de la Fiesta del Libro de 1938, al mismo tiempo que defendía las depuración de los fondos bibliográficos patrios, arremetía contra las publicaciones de la filial argentina de Espasa-Calpe:

Es necesario este Tribunal rígido de Inquisición. Hoy es la Fiesta del libro. Desde hace años funciona en nuestra España una filial o Sucursal de la Editora Espasa-Calpe. ¿Ha pasado (preguntamos) por algún tamiz el historial y los fondos editoriales de esa casa, anteriores a la guerra? ¿Es posible tener una casa en Madrid, otra en san Sebastián y otra en Buenos Aires? ¡Los triángulos nos escaman demasiado! Y vamos a precisar más, porque el escándalo es intolerable. Hoy en todos los escaparates de las librerías se expone la Colección Austral de la Espasa-Calpe. Tiene mucho que purgar y que rectificar esta Editora. Pues bien: sin enterarse por lo visto del nuevo espíritu de España nos presenta títulos como éstos: Descartes, Discurso del Método, condenado por la Iglesia, en el Índice. El Matrimonio de Compañía, de Lindsay y Evan. De Ortega y Gasset (¡cómo no!) su Rebelión de las Masas y Temas de nuestro tiempo. El estúpido payaso Ramón Gómez de la Serna, Russell y Thomas Mann. ${ }^{10}$ [La cursiva es mía, salvo los títulos de los libros.]

Sorprende la fijación del órgano de Falange contra el fondo de Espasa-Calpe, editorial comercial convencional, con gran capital social y de carácter conservador. Pero, sobre todo, en este artículo se atacaba a los títulos de la colección Austral. Recordemos que la sucursal argentina de Espasa-Calpe se había independizado de la casa madre en abril de 1937 por las dificultades derivadas de la guerra, constituyéndose en sociedad anónima, y había emprendido su labor editora con Gonzalo Losada y Julián Urgoiti, aunque en octubre de ese mismo año se puso al frente de la misma Manuel Olarra (Olarra Jiménez, 2003). Destacó especialmente entre su producción la colección de bolsillo Austral, iniciada por Guillermo de la Torre y Gonzalo Losada a comienzos de 1938. Cada mes se editaban entre 10 y 20 títulos nuevos en tiradas de 12.000 ejemplares, exportando más del 30\%. Estas obras llegaban a la España en guerra, sorteando el control de la censura franquista, y por eso eran condenadas por Yzurdiaga. El primer libro publicado fue La rebelión de las masas de Ortega y Gasset, uno de los ejemplares que desdeñaba el periódico falangista.

${ }^{10}$ En Arriba España, Pamplona, 23 de abril de 1938, p. 1. 
Prácticamente al mismo tiempo, en julio de 1938, el propio Ortega y Gasset escribió preocupado a su amigo Gregorio Marañón señalando la mala situación de Espasa-Calpe Argentina por motivos de dirección y financieros, y advirtiéndole que estaba en juego el control español del libro castellano en la América hispana. Aparte de esta aguda reflexión, que anticipaba el declive de la industria editorial españolas en esas tierras, sorprende el comentario sobre la aparición de un nuevo sello: “[...] Losada se ha separado con algunos muchachos de izquierda y ha creado una editorial cuyo capital, de cuantía desconocida, no tiene un origen todavía notorio. Es resueltamente una editorial roja” (López Vega, 2008: 198). No deja de sorprender que tanto Yzurdiaga, como Ortega y Gasset y Marañón estuvieran en el mismo bando de la guerra, aunque el religioso participando muy activo en el interior del país, y los otros dos intelectuales desde sus respectivos exilios apoyando la causa franquista y con hijos que lucharon en las filas "nacionales" (Morán, 1998: 57-58). De este modo en el periódico falangista se condenaban obras de Ortega y Gasset y el filósofo acusa de roja a la casa Losada. Julián Urgoiti, Gonzalo Losada y Guillermo de Torre se marcharon de Espasa Calpe Argentina por razones políticas y profesionales en julio y agosto de 1938, respectivamente. Ambos acabaron participando en dos de las principales editoriales argentinas donde el papel del exilio será determinante: Losada y Editorial Sudamericana (Zulueta, 1999; De Diego, 2006: 91-123; y Sánchez Illán, 2015: 549-595). Aunque Losada no era estrictamente un exiliado político porque llevaba afincado en Buenos Aires desde 1928, se identificó con la causa republicana (Gudiño Kieffer, 2005). La editorial que lleva su apellido comenzó a andar en agosto de 1938 con Guillermo de Torre, Atilio Rossi, Amado Alonso, Pedro Henríquez Ureña y Francisco Romero, aunque poco tiempo después se sumaron los hermanos Jiménez de Asúa, Teodoro Becú y Lorenzo Luzuriaga. Aparte de publicar títulos de literatura española y universal se hizo eco de la producción del exilio, editando obras de Alejandro Casona, Luis Cernuda, León Felipe, Pedro Salinas, Arturo Barea, Rosa Chacel, Américo Castro, Francisco Ayala, Rafael Alberti o Ma Teresa León entre otros. Además algunos de estos autores y otros refugiados colaboraron como traductores y directores literarios de colecciones. En este sentido sobresalen los testimonios de Alberti y María Teresa sobre el apoyo personal, literario, y financiero que Losada les prestó en su exilio argentino frente al menos 
complaciente de Francisco Ayala como traductor y autor de la casa. ${ }^{11}$ En diciembre de 1938 se fundó Editorial Sudamericana por un heterogéneo grupo de intelectuales y socios capitalistas, entre los que destacaban Victoria Ocampo o Rafael Vehils pero, acabó vinculada a la figura del librero catalán Antonio López Llausás, que llegó en septiembre de 1939 desde su exilio en Francia para trabajar como gerente de la empresa junto a Julián Urgoiti. Antes de la guerra había sido director de la librería y editorial Catalònia en la ciudad condal (López Llovet, 2004). Aunque en su catálogo predominaron más obras traducidas también recogió obras de los expatriados como Salvador de Madariaga, José Ferrater Mora, Claudio Sánchez Albornoz, o Jorge Guillén. Incluso estas editoriales contribuyeron a la renovación historiográfica española y a la polémica intelectual sobre la idea y la esencia de España entre Américo Castro y Claudio Sánchez Albornoz, ambos exiliados, ya que Losada publicó la obra del primero, España en su historia en 1948 y Sudamericana la de segundo, España: enigma histórico en 1956.

El distribuidor e importador Joaquín de Oteyza estableció un importante depósito de libros argentinos en 1945 en un antiguo frontón de la madrileña calle Alcántara. Para poner en marcha el negoció organizó una primera entrega de 24.000 paquetes de cinco kilos de libros, que fueron llegando poco a poco por la falta de vagones de mercancías, retrasos en el servicio de Correos y en Aduanas además de los trámites de censura, que apartaban títulos prohibidos y otros sospechosos, pendientes de revisión. A los pocos meses de su inauguración, el 10 de noviembre, se personaron dos agentes del cuerpo general de policía, vinculados a la Brigada de Investigación Criminal de la Dirección General de Seguridad para cerrar y sellar los locales por las graves transgresiones que Oteyza había cometido de las vigentes disposiciones de censura. Se precintó incluso el buzón de correos, impidiendo acceder a la correspondencia y por tanto condenando a la incomunicación con editores, libreros y bancos. Ante esta situación Oteyza realizó numerosas gestiones para conseguir alguna explicación y solución al precintado de su Depósito pero, resultaron infructuosas. Debido al silencio administrativo del Director General de Propaganda de la Vicesecretaría de Educación Popular, recurrió al director del INLE, Julián Pemartín,

\footnotetext{
11 “Pero todo nos los solucionó una persona que, entre otras, queridísimas luego, nos esperaba en el puerto: nuestro grande y generoso Gonzalo Losada, un nuevo editor lleno de genio e iniciativas, un verdadero, adelantado, quien nos resolvió nuestra tan incierta situación. Él me contrató en seguida mi nuevo libro, Entre el clavel y la espada, que yo había comenzado a escribir en Francia, durante mis noches como locutor de la radio Paris-Mondial. Nos pagó durante varios meses los derechos del libro, como también el resto que me debía por mi Antología poética, publicada unos meses antes. [...]. Publicó, al fin, todos mis libros y algunos de María Teresa” (Alberti, 1998: 135). “A Losada lo sentimos en todo momento cerca. Le gustaba sentarse a nuestra mesa, que Aitana le llamara padrino, [...] Durante años y años, Gonzalo Losada no ha hecho más que abrir libros y presidir consejos, durante años y años ha dado el pase y edítese a nuestros libros. ¿Cómo no darle las gracias?” (León, 1999: 420-422). "En cuanto a mí, continué por lo pronto traduciendo para Losada, y procuré aprender a defenderme, aunque nunca -la verdad- con demasiada destreza, de sus prácticas depredadoras". "El libro [Tratado de Sociología de 1947] del que se tiró una edición considerable, sería para Losada un éxito económico. Lo vendió muy bien en todas partes, agotó la edición y, para colmo, tuvo la avilantez de retacearme mediante varios trucos el pago de mis derechos de autor con un descaro tan grande que terminé por llamarle ladrón en su cara" (Ayala, 2001: 266 y 328).
} 
consiguiendo que se pusiese fin a la clausura de su depósito. Tras diez días y gracias a la intervención de las altas esferas, aparte de las protestas de editoriales españolas como Sopena, Gili y Dossat por los enormes perjuicios que les ocasionaba este cierre, Oteyza reabrió su almacén. Estas casas españolas tenían miles de ejemplares retenidos ya que habían entregado a este comerciante su representación comercial para el mercado argentino. Pero el oficio de la Sección de Censura del Ministerio de Educación Nacional, que levantaba la sanción, imponía una condición que dilataba notablemente el funcionamiento normal del negocio. La reapertura exigía la presencia de un funcionario de la Subsecretaría y otro del INLE en el depósito para comprobar los títulos antes de distribuirlos entre los profesionales del libro del país. Oteyza se volvió a poner en contacto con Julián Pemartín ya que este procedimiento retrasaba mucho su trabajo y amenazó con denunciar al Ministerio. Además, como pasaban los días y no se personaban los citados funcionarios, escribió nuevamente a la Vicesecretaría de Educación Popular anunciando una demanda contra los máximos responsables del sistema censorio, el ministro Gabriel Arias Salgado y el jefe de Censura de la Vicesecretaría de Educación Popular, Patricio González de Canales, aparte de plantear un conflicto en las relaciones diplomáticas entre España y Argentina por lesión a los intereses de los editores argentinos que representaba. Tras arruinarle la campaña navideña de 1945, y después de estas medidas de presión consiguió recuperar su actividad comercial pero, con numerosas trabas burocráticas (Mangada y Pol, 1996: 189-212). Este episodio refleja perfectamente las enormes dificultades que conllevaron las relaciones editoriales entre América y España durante la guerra y la larga posguerra. En este sentido cabe destacar que el libro americano y, en particular el argentino, aparte del grave problema de la censura, se encontraba con importantes obstáculos burocráticos que entorpecían su entrada en España, relacionados con el retraso en la obtención de las licencias de importación, la escasez de divisas, la dificultad de encontrar barcos para el transporte de libros, el encarecimiento de los fletes, y el gravamen de importación a los libros, a pesar del Convenio Cultural firmado entre ambos países en 1942. El incumplimiento sistemático de las cláusulas firmadas llevó a firmar uno nuevo en 1946. En definitiva, los trámites administrativos, cambiarios y políticos impedían la libre circulación de libros extranjeros y paradójicamente se convirtieron en una suerte de proteccionismo del libro español frente a la producción americana (Larraz, 2010: 157-182).

Con todos los títulos que la censura le impidió introducir en España Oteyza creó una biblioteca en su particular museo, La Venta del Libro, situada en Aravaca a nueve kilómetros de Madrid. Estos casi cuatrocientos libros, en su mayoría publicados por editoriales argentinas, recogían parte de la historia de la censura española. De hecho, cuando Gabriel Arias-Salgado visitó la finca en 1952, Oteyza se jactó de tener la biblioteca más grande de España dedicada por el ministro y le mostró un ejemplar con el oficio del Ministerio prohibiendo la circulación de dicha obra. Entre estos libros figuraban varias obras de Federico García Lorca, Rafael Alberti, Pío Baroja, Luis Jiménez de Asúa, Lorenzo Luzuriaga, o Jules 
Romain, y títulos como Lisístrata. Las Tesmoforias. Las ranas de Aristófanes, Las flores del mal de Charles Baudelaire, La cabeza del cordero de Ayala, Como quien espera el alba, 1941-1944. La realidad y el deseo de Luis Cernuda, La náusea de Jean Paul Sartre o Canto a mí mismo de Walt Whitman, todas ellos publicadas por la editorial Losada, el sello que más se repitía en este catálogo de obras prohibidas. También figuraban otras casas como Poseidón, Santiago Rueda, Guillermo Kraft, El Ateneo, Pleamar, Atlántida o Argonauta, y otros autores muy diversos como Niceto Alcalá-Zamora, Balzac, Clara Campoamor, Rosa Chacel, Chéjov, Fernando de los Ríos, John Dos Passos, Dostoievski, Goethe, Gorki, Hermann Hesse, Víctor Hugo, James Joyce, Nietzsche, Ángel Ossorio, Marcel Proust, o Jakob Wassermann (Mangada y Pol, 1996: 275 y 277-286).

A pesar de todas las dificultades políticas y las trabas burocráticas, existieron contactos entre la España del interior y la del exilio. El interés de los exiliados por todo lo relacionado con su tierra y la curiosidad de los españoles de la Península por conocer la obra de los desterrados propiciaron las relaciones culturales y personales, aunque de forma muy limitada y fragmentaria. ${ }^{12}$ Como sostiene José María Naharro-Calderón, las publicaciones de los exiliados circularon en España aunque de manera reducida, tanto en las esferas oficiales para contrarrestar su labor como entre los particulares con carácter disidente e informativo. El último objetivo de los exiliados era introducir sus publicaciones en España, que los lectores españoles conociesen y leyesen sus obras. Tras sortear el sistema censorio y las inspecciones policiales, los títulos llegaban al país aunque la distribución siempre fue deficitaria. Pero no alcanzaron al gran público, que tenía un gran desconocimiento de estos autores y de sus obras. Así el primer libro que tradujo Francisco Ayala en 1944 para Losada, Cuadernos o Apuntes de Malte Laurids Brigge de Rainer Maria Rilke, se introdujo "a través de los pocos ejemplares penosamente llegados hasta entonces hasta este lado del Atlántico", aunque tuvo un efecto "en los deprimidos ambientes literarios peninsulares” (Ayala, 2001: 265). Un ingenuo lector preguntaba al director de la revista Ínsula en marzo de 1946 en qué editoriales podía encontrar obras de García Lorca, Alberti, Salinas, Cernuda o Altolaguirre, entre otros. En la respuesta se reconocía implícitamente la imposibilidad de leer a estos autores ya que sus obras no se publicaban en España y las ediciones de América estaban prohibidas, tan sólo contemplaba la posibilidad de encontrar algún libro anterior a la guerra en librerías de viejo (Larraz, 2009: 169). Se emplearon numerosas argucias para burlar los controles aduaneros. Incluso se utilizó la valija diplomática o el buque-escuela Juan Sebastián Elcano para introducir libros prohibidos desde los años 40 como demuestran las relaciones y los intercambios bibliográficos establecidos entre Juan Guerrero Ruiz de la editorial Hispánica con Guillermo de la Torre, director literario de Losada, y con Julián Calvo, vinculado a Fondo de Cultura Económica, y éste último con Enrique Canito, propietario de

12 Sobre el exilio intelectual y cultural vid. Manuel Aznar Soler, 2004: 582-634; Alicia Alted, 2005; Francisco Caudet, 2005; Antolín Sánchez Cuervo (coord.), 2008; José María López Sánchez, 2013. 
la librería Ínsula de Madrid. De hecho Guerrero consiguió en 1945 la exclusiva de Losada para la introducción de sus libros en España, aunque siempre en círculos muy reducidos y con muchas salvedades. Pero el proyecto de establecer un gran centro distribuidor en México de libros españoles a cambio de la exportación de libros editados en América a través de Hispánica e Ínsula se frustró (Naharro Calderón, 1994: 382-403). Otra práctica muy habitual para introducir títulos no permitidos era modificar la factura de origen, incluyendo títulos autorizados, para que fuera aprobada por el Departamento de Censura y los funcionarios de Aduanas, que por rutina o bien por complicidad no abría los paquetes para comprobar su contenido. León Sánchez Cuesta obtenía títulos de Losada con dificultades a través del importador Joaquín de Oteyza. Sin embargo, fue reacio a recibir regularmente libros de fuera para distribuirlos en el país como había hecho antes de la guerra con los títulos del sello argentino Sur de Victoria Ocampo. Debido a los problemas que le podía acarrear, era más partidario de importar títulos sueltos y en pocas cantidades. De esta manera consiguió ocho de los veinte ejemplares que llegaron a España del libro de Jorge Guillén, Cántico, editado en Buenos Aires por la editorial Sudamericana en 1950 en su cuarta y definitiva versión. En octubre de 1949 se vio obligado a rechazar la propuesta desde México del poeta Juan José Domenchina, antiguo amigo y cliente, para distribuir su libro Perpetuo Arraigo, que a priori no tropezaría con los rigores de la censura al tratarse de una obra exclusivamente lírica, debido a las restricciones comerciales existentes entre ambos países. Y en la carta de contestación concluía de manera amarga sobre las difíciles relaciones entre el exilio y la Península:

Es verdaderamente lamentable la situación de aislamiento o separación en que vivimos. El escritor español, de España, necesita se haga posible el envío de sus libros al extranjero como necesita recibir y conocer lo que hacen afuera. No es posible continuemos enterándonos unos de otros por los préstamos que los felices mortales que reciben algo pueden hacernos. ${ }^{13}$ [La cursiva es mía.]

Otro motivo que explica la débil difusión de esta literatura prohibida entre círculos minoritarios era el precio que alcanzaban una vez que llegaban a las trastiendas de las librerías especializadas debido a los riesgos que implicaba y a la escasez de oferta. Así los ejemplares de la Biblioteca Contemporánea de Losada oscilaban entre las 6 y las 10 pesetas, mientras que los de Austral valían 4,50 pesetas, y cada tomo de los ocho que componían las Obras completas de García Lorca, que por primera vez editó Losada entre 1938 y 1946, recopiladas y prologadas por Guillermo de Torre, se vendían a 16 pesetas. Los libros de Emecé alcanzaban entre 20 y 30 pesetas cuando en España libros de características similares costaban unas 16 pesetas. Los títulos de la colección Horizonte de la editorial Sudamericana llegaban a las 50 pesetas, y la obra de Max Aub, San Juan, editada por Edhasa en 1953, llegó a venderse a 112,50

\footnotetext{
${ }^{13}$ Vid. carta del 14 de octubre de 1949 dirigida a Juan José Domenchina en Archivo de la Residencia de Estudiantes. Cartas de León. Copias, LSC 21/65/2, y la propuesta de Domenchina a León, en LSC 6/41/2.
} 
pesetas (Larraz, 2010: 183-185). Sólo la élite intelectual y profesional podía permitirse pagar esos precios. De hecho esta fue una de las motivaciones que llevaron a Francisco Pérez González a especializarse en este tipo de comercio ilegal y el origen de su gran imperio librero, según su propio testimonio (Lago Carballo y Gómez Villegas, 2006: 181-182). También es verdad que no podemos cuantificar el efecto multiplicador de la lectura de un libro prohibido debido a la atracción que generaba al tratarse de un bien escaso muy preciado, y explica su difusión más allá del propietario del ejemplar.

Asimismo cabe destacar la llegada de libros prohibidos a través de distribuidores como José Latorre, Rufino Torres Castañeira, antiguo guardia civil conocedor de las prácticas y costumbres de las fuerzas del orden, o Francisco Pérez, librero argentino pero afincado en Santander que creó la Distribuidora Hispano Argentina, sin olvidar el papel pionero de Oteyza ya señalado. También fue importante el papel de las delegaciones de algunas firmas mexicanas y argentinas en España como Edhasa (Editora y Distribuidora Hispanoamericana Sociedad Anónima), establecida en 1946 y vinculada a la Editorial Sudamericana de Antonio López Llausás, y a las filiales de Fondo de Cultura Económica, Grijalbo o Siglo XXI a partir de los primeros años sesenta. Además del catálogo de Sudamericana, Edhasa distribuía obras de Emecé y Fondo de Cultura. Estas casas introdujeron libros prohibidos pagando altas cantidades a los funcionarios de aduanas y de la censura, aparte de abordar la vía legal, aceptando los recortes de la censura, o bien a partir de la Ley de Prensa de 1966 jugándosela al máximo aprovechando la supresión del trámite previo censorio. En este sentido José-Carlos Mainer ha demostrado asimismo la recepción de las letras del exilio desde mediados de los años 40 a través de algunas revistas literarias como Ínsula, Índice o Papeles de Son Armadans y en editoriales como Seix Barral, Taurus o Guadarrama a partir de la segunda mitad de la década de los cincuenta. Especial atención merece la publicación en Barcelona a partir de 1963 de obras de Corpus Barga, Max Aub, Francisco Ayala, Mercé Rodoreda o Salvador de Madariaga en la colección "El Puente" de Edhasa, dirigida por Guillermo de Torre, a pesar del rechazo sistemático por tres veces del Ministerio de Información y Turismo en 1961 al proyecto editorial "El Puente" (Mainer, 1998: 395-415). Pero las relaciones nunca fueron ni fáciles ni fluidas, siempre estuvieron acompañadas de obstáculos y restricciones, ya que en España imperaba la cultura de la Victoria y muchos autores y títulos fueron prohibidos, o en el mejor de los casos cercenados por la censura. Estas circunstancias explican que la obra de los exiliados no sólo sea desconocida para la mayoría de los ciudadanos del siglo XXI sino que todavía no esté incorporada con pleno derecho en el canon literario español del siglo XX junto a la producción de los españoles de la Península que publicaron durante y bajo el franquismo. Otra grave consecuencia que llega hasta la actualidad es la circulación de numerosos títulos extranjeros y de exiliados mutilados debido a las sucesivas reediciones y reimpresiones que siguen la primera edición autorizada por la censura franquista por ignorancia, comodidad y motivos económicos de la mayoría de las casas editoriales existentes. 
Sobre la cuestión central de la censura destaca el testimonio de Francisco Ayala, que en su exilio argentino recibió una carta del jefe de censura, Juan Beneyto, donde agregaba como posdata: "Felices ustedes que pueden publicar lo que quieren”. También cuenta en sus memorias cómo Julián Urgoti, gerente de la editorial Sudamericana, en 1948, a la vuelta de un viaje a España para ver si conseguía unas normas de censura fijas a las que atenerse para introducir libros en España, le comentó las causas de las arbitrariedades de la misma. Este editor se quejaba de las molestias y perjuicios causados por el cambio de criterios ya que ocurría con demasiada frecuencia que se vetaba la entrada de un libro autorizado previamente, o bien se prohibían obras como La vida de las abejas de Maeterlinck sin saber por qué. El mismo Beneyto le respondió que esas variaciones respondían a que era muy habitual la irrupción en el despacho de un

colérico sacerdote, y esgrimiera un libro protervo que, inconcebiblemente, se hallaba a la venta en la sagrada España, para pedir explicaciones acerca de cómo tal horror había podido consentirse. Y entonces el señor jefe de la censura, por apaciguar la ira santa de aquel ministro de Dios, inquiriría cuál de sus subordinados había recomendado la aprobación del libro nefando, le hacía comparecer a su presencia, y en la del reclamante le echaba tremendo rapapolvo, con graves amenazas al culpable y humildes disculpas al furioso. (Ayala, 2001: 333-334)

Después de este episodio ese infeliz censor "ya no se atreve en una temporada a la aprobación ni de un libro de cocina” (Ayala, 2001: 334). De este modo funcionaba la temible censura, arbitrariamente, sin criterios definidos, causando graves perjuicios a creadores y editores de ambos lados del Atlántico. En este sentido la negativa de Francisco Ayala a someterse a los rigores de la censura, mutilando sus textos originales, impidió que aparecieran en España antes de los años 70 dos obras que abordaban el tema de la guerra civil, Los usurpadores y La cabeza del cordero, ambos publicados originalmente en 1949 por Sudamericana y Losada, respectivamente. Y esa demora, a pesar de que para José Luis López-Aranguren en 1953 el escritor granadino representaba a los desterrados moderados frente a los irreductibles de Max Aub, León Felipe o Rafael Alberti (López Aranguren, 1953). Finalmente fueron editadas en Barcelona por Seix Barral en 1971 y 1972. Este fue también el motivo por el que tuvo que renunciar a ver publicadas sus Obras narrativas completas en Madrid por la casa Aguilar a fines de los años 60, que acabaron viendo la luz en la sucursal de México en 1969. Aparte de los efectos devastadores que tuvo la censura para el mundo de la cultura y el negocio editorial, como reflejan estos y otros muchos casos, todavía resultan más relevantes sobre los límites de las relaciones entre el exilio y la España de la dictadura las consecuencias que tuvo la reseña de las dos obras prohibidas de Ayala en la revista Ínsula:

El libro tuvo en Argentina muy buena acogida crítica; y en Madrid, Ricardo Gullón, que ya había escrito en Ínsula sobre Los usurpadores, llamó la atención de los lectores sobre La cabeza de cordero. A quien su artículo puso sobre aviso fue, sin embargo, a los perros guardianes del 
régimen franquista, pues el diario Arriba se apresuró a publicar un editorial soez y amenazador, con la finalidad evidente de -dado que yo estaba fuera de su alcance- intimidar a los hombres admirables que en esa meritoria revista, Ínsula, se esforzaban entonces por mantener un rescoldo del espíritu liberal en España. Sólo pude felicitarme de estar lejos cuando leí el recorte del miserable artículo que alguien me enviara. (Ayala, 2001: 331) ${ }^{14}$

14 Y seguía a continuación: "Mucho más tarde, bastantes años después, hubo de acudir a mi memoria ese episodio en ocasión de que un joven periodista vino aquí, a casa, y entre las preguntas que quería hacerme quiso saber por qué había abandonado yo la Patria tras la guerra. 'Hombre, porque quería seguir viviendo', fue mi respuesta. '¡Cómo! ¿A usted, señor Ayala?'. No podía creerlo. ¡Bendita inocencia, la de los nacidos durante los veinticinco años de paz!”. 


\section{Bibliografía}

Alberti, Rafael (1998). La arboleda perdida, 2. Tercero y Cuarto libros (1931-1987). Madrid: Alianza Editorial.

Alted, Alicia (2005). La voz de los vencidos. El exilio republicano de 1939. Madrid: Aguilar.

Amo, Julián y Shelby, Charmion (1950). La obra impresa de los intelectuales españoles en América, 1936-1945. Stanford: Stanford University Press.

Aróstegui Sánchez, Julio. "Opresión y pseudo-juricididad: de nuevo sobre la naturaleza del franquismo", Bulletin d'Histoire Contemporaine de l'Espagne 24 (1996): 31-46.

Aróstegui Sánchez, Julio (2012). "Una dictadura "sui generis": ideología de exclusión y aparato represivo". Segura, Antoni, Mayayo, Andreu y Abelló, Teresa (dirs.) La dictadura franquista. La institucionalizació d'un règim. Barcelona: Universitat de Barcelona: 423-456.

Ayala, Francisco (2001). Recuerdos y olvidos. Madrid: Alianza.

Aznar Soler, Manuel (2004). “1939: Literatura y cultura del exilio republicano español”. Juliá, Santos (coord.). República y guerra civil. Tomo 40 de la Historia de España de Ramón Menéndez Pidal, dirigida por José María Jover. Madrid: Espasa-Calpe: 582-634.

Calderón, José Ma Naharro (1994). Entre el exilio y el interior: el "entresiglo" y J. R. Jiménez. Barcelona: Anthropos, 1994.

Caudet, Francisco (2005). El exilio republicano de 1939. Madrid: Cátedra.

Delgado Gómez-Escalonilla, Lorenzo (1992). Imperio de papel: acción cultural y política exterior durante el primer franquismo. Madrid: CSIC.

Delibes, Miguel y Vergés, Josep (2002). Correspondencia, 1948-1986. Barcelona: Destino.

Díaz Arciniega, Víctor (1996). Historia de la casa. Fondo de Cultura Económica (1934-1996). México: Fondo de Cultura Económica.

Diego, José Luis de (2006). “1938-1955. La “época de oro” de la industria editorial”. De Diego, José Luis (dir.) Editores y políticas editoriales en Argentina, 1880-2000. Buenos Aires: Fondo de Cultura Económica: 91-123.

Fernández Moya, María. "Editores españoles a ambos lados del Atlántico. El sector editorial republicano y la edición en la España franquista”. Historia del Presente 12 (2008): 97-110.

Fernández Moya, María. “Editoriales españolas en América Latina. Un proceso de internalización secular". ICE: Revista de Economía 849 (2009a): 65-77. 
Fernández Moya, María. "Multinacionales del castellano. La internalización del sector editorial español (1898-2008)". Revista de Historia Industrial 40, (2009b): 23-49.

Fernández Moya, María. "La promesa del gran mercado del libro. Un siglo de editoriales españolas en Argentina (1900-2008)". Revista de la Historia de la Economía y de la Empresa 5 (2011): 205-237.

Fernández Moya, María (2015). “La internalización de los editores. Los mercados exteriores”. Martínez Martín, José Antonio (dir.) Historia de la edición en España 1939-1975. Madrid: Marcial Pons: 575-595.

Férriz Roure, Teresa (1998). La edición catalana en México. México: El Colegio de Jalisco.

Gili, Gustavo (1944). Bosquejo de una política del libro. Barcelona.

Gudiño Kieffer, Eduardo (2005). Losada. Gonzalo Losada, el editor que difundió el libro argentino en el mundo. Buenos Aires: Editorial Dunken.

Lago Carballo, Antonio y Gómez Villegas, Nicanor (eds.), (2006). Un viaje de ida y vuelta. La edición española e iberoamericana (1936-1975). Madrid: Siruela.

Larraz, Fernando (2009). El monopolio de la palabra. El exilio intelectual en la España franquista. Madrid: Biblioteca Nueva.

Larraz, Fernando (2010). Una historia transatlántica del libro. Relaciones editoriales entre España y América latina (1936-1950). Gijón: Trea.

Larraz, Fernando (2014). Letricidio español. Censura y novela durante el franquismo. Gijón, Trea.

León, Ma Teresa (1999). Memoria de la melancolía. Madrid: Castalia.

López-Aranguren, José Luis (1953). "La evolución espiritual de los intelectuales españoles en la emigración”. Cuadernos Hispanoamericanos 38 (1953): 123-158.

López Llovet, Gloria (2004). SUDAMERICANA. Antonio López Llausás, un editor con los pies en la tierra. Buenos Aires: Editorial Dunken.

López Sánchez, José María (2013). Los refugios de la derrota. El exilio científico e intelectual republicano de 1939. Madrid: CSIC/La Catarata.

López Vega, Antonio (2008). Epistolario inédito. Marañón, Ortega, Unamuno. Madrid: Espasa-Calpe. Mainer, José-Carlos (1971). Falange y literatura. Barcelona: Labor. 
Mainer, José-Carlos (1989). "La segunda guerra mundial y la literatura española: algunos libros de 1940-1955”. García Delgado, José Luis (ed.) El primer franquismo. España durante la segunda guerra mundial. Madrid: Siglo xxi: 245-268.

Mainer, José-Carlos (1998). "El lento regreso: textos y contextos de la colección El Puente (1963-1968)”. Aznar Soler, Manuel (ed.) El exilio literario español de 1939: Actas del I Congreso Internacional. Vol. I. San Cugat del Vallés: 395-415.

Manfredi, Domingo (1963). Instituto Nacional del Libro Español. Madrid: Publicaciones Españolas.

Mangada, Alfonso y Pol, Jesús (1996). Libreros y editores (1920-1960). Joaquín de Oteyza: Biografía de un empresario del libro. Madrid: Paraninfo.

Martínez Rus, Ana. "La proyección editorial en los mercados americanos (1901-1936)". Pliegos de Bibliofilia, 12 (2000): 31-53.

Martínez Rus, Ana (2001). "El comercio de libros. Los mercados americanos”. Martínez Martín, José Antonio (dir.) Historia de la edición en España, 1836-1936. Madrid: Marcial Pons: 269-305.

Martínez Rus, Ana. "La industria editorial ante los mercados de Hispanoamérica, 1892-1936". Hispania, LXII/3, 212 (2002): 1021-1058.

Martínez Rus, Ana (2003). La política del libro durante la Segunda República, socialización de la lectura. Gijón: Trea.

Martínez Rus, Ana (2007). "San León Librero": Las empresas culturales de Sánchez Cuesta. Gijón: Trea.

Martínez Rus, Ana (2008). "Exportando cultura: las estrategias transatlánticas de los editores, 1892-1936”. Revista de la Historia de la Economía de la Empresa 2 (2008): 183-204.

Martínez Rus, Ana (2011). "Barcelona y Madrid ante el reto americano: las expectativas de la industria del libro”. Catalán i Vidal, Jordi, Miranda, José Antonio, y Ramón-Muñoz, Ramon, (dirs.) Distritos y clusters en la europea del sur. Madrid: LID Editorial: 81-100.

Martínez Rus, Ana (2012). "La represión cultural: libros destruidos, bibliotecas depuradas y lecturas vigiladas”. Aróstegui, Julio (coord.) Franco: la represión como sistema. Barcelona: Flor del Viento: $365-415$.

Martínez Rus, Ana (2013). “Expolios, hogueras, infiernos. La represión del libro”. Represura, http:// www.represura.es, 8 (2013).

Martínez Rus, Ana (2014). La persecución del libro. Hogueras, infiernos y buenas lecturas (1936-1951). Gijón: Trea. 
Martínez Rus, Ana y Sierra Blas, Verónica (2012). "Libros culpables: hogueras, expurgos y depuraciones. La política represiva del franquismo, 1936-1939”. Segura, Antoni, Mayayo, Andreu y Abelló, Teresa (dirs.) La dictadura franquista. La institucionalizació d'un règim. Barcelona: Universitat de Barcelona: 143-157.

Morán, Gregorio (1998). Elmaestro en el erial. Barcelona: Tusquets.

Olarra Jiménez, Rafael (2003). Espasa-Calpe. Manuel Olarra, un editor con vocación hispanoamericana. Buenos Aires: Editorial Dunken.

Suárez, Luis (1982). "Prensa y libros. Periodistas y editores". VV. AA., El exilio español en México, 1939-1982. México: Fondo de Cultura Económica: 601-621.

Piedrafita Salgado, Fernando (2003). Bibliografía del exilio republicano español (1936-1975). Madrid: Biblioteca Nueva.

Pochat, María Teresa (1991). "Editores y editoriales”. Sánchez-Albornoz, Nicolás (comp.) El destierro español en América. Un trasvase cultural. Madrid: Instituto de Cooperación Iberoamericana: 163-176.

Sagastizábal, Leandro de (1991). "Editores españoles en el Río de la Plata”. Clementi, Hebe (coord.) Inmigración española en la Argentina, Buenos Aires: Oficina Cultural de la Embajada de España: 259-272.

Sánchez Cuervo, Antolín (coord.) (2008). Las huellas del exilio. Expresiones culturales de la España peregrina. Madrid: Tebar.

Sánchez Illán, Juan Carlos (2015). “Los editores españoles en el exterior. El exilio”. Martínez Martín, José Antonio (dir.) Historia de la edición en España 1939-1975. Madrid: Marcial Pons: 549-595.

Santonja, Gonzalo (1997). Al otro lado del mar. Bergamín y la editorial Séneca (México, 1939-1949). Barcelona: Círculo de Lectores.

Santonja, Gonzalo (2003). Los signos de la noche. De la guerra al exilio. Historia peregrina del libro republicano entre España y México. Madrid: Castalia.

Zuleta, Emilia de (1999). Españoles en la Argentina. El exilio literario de 1936. Buenos Aires: Ediciones Atril. 